\title{
Integral sliding-mode controller for maximum power point tracking in the grid-connected photovoltaic systems
}

\author{
Nour-Eddine Tariba, Naima Ikken, Ahmed Haddou, Abdelhadi Bouknadel, \\ Hafsa El Omari, Hamid El Omari \\ Laboratory of Renewable Energy, Environment and Development (LERED). Faculty of Science and Technology, \\ University Hassan $1^{\text {st }}$, Morocco
}

\section{Article Info}

Article history:

Received Mar 19, 2019

Revised Aug 11, 2019

Accepted Aug 29, 2019

Keywords:

DC/DC converter

Photovoltaic systems

MPPT

Sliding mode control

\begin{abstract}
The output power generated in the photovoltaic modules depends both on the solar radiation and the temperature of the solar cells. To maximize the efficiency of the system, it is required to monitor the maximum power point of the photovoltaic system. For this purpose, monitoring the maximum power point (MPPT) of photovoltaic systems should be as quick and accurately as possible for increasing energy production, which ultimately increases the cost-efficiency of the photovoltaic system. This paper proposes a new approach for MPPT) using the concept of the integral sliding mode controller (ISMC) to ensure fast and precise monitoring of the peak power. The performance of the ISMC is significantly influenced by the choice of the sliding surface. To assess the reliability ISMC control, the results have been compared with those of a PI controller. The results obtained are used to evaluate the performance of the ISMC strategy under different climatic conditions. Finally, the effectiveness of the proposed solution is confirmed using simulations in PSIM tools and experimental results were used to evaluate the effectiveness of the proposed approach.
\end{abstract}

Copyright (ㅇ 2020 Institute of Advanced Engineering and Science. All rights reserved.

\section{Corresponding Author:}

Nour-Eddine Tariba,

Laboratory of Renewable Energy, Environment and Development (LERED),

Faculty of Science and Technology,

University Hassan $1^{\text {st }}$,

BP 577, 2600, Settat-Morocco.

Email: NoureddineTariba@gmail.com

\section{INTRODUCTION}

The MPPT method for photovoltaic systems intends to identify the operating point where the product of output voltage and current is most significant. Theoretically, the GPV produces maximum power when there is a matching impedance between GPV and load. Therefore, the MPPT process guarantees that the output impedance and the load impedance of the GPV cells are gradually harmonized. As climatic factors influence the output impedance of the GPV, MPP can be achieved if the load impedance is adjusted in real-time to monitor the output impedance of the GPV. And for better understanding, the equivalent impedance Ropt of GPV is defined as the ratio between the MPP voltage VMPP and the MPP current IMPP, (i.e. Ropt= UMPP/IMPP). The state of the environment changes, and so Ropt. Nevertheless, some problems of load adaptation exist as described in [1,2].

The most popular MPPT algorithms are the Incremental Conductance INCC which is based on the analysis of the conductance variation and its influence on the operating point and the perturb and observe $(\mathrm{P} \& \mathrm{O})$ which is consist to disturb the PV voltage with stepsize voltage and analyzing the resulting power [3-4]. The result for these algorithms is the voltage VMPP (resp IMPP) witch corresponds to the maximum power. The most significant concern for all these MPPTs is the degree of dependency of 
the MPPTs monitoring response on the size of the disturbance. Furthermore, the tracking signal oscillates approximately around its reference point, and this even under steady-state conditions [5]. It is crucial to use a second loop, generally a PI controller to keep the MPP tracking accuracy [6]. These control laws may be insufficient because they are not reliable, particularly when the requirements on dynamic characteristics and accuracy are very strict.On the other hand, it's important to linearize the system model around a specific operating point, which is usually the PPM at a particular condition. Since the PV module and the DC/DC converter are non-linear by their nature, however, the performance and stability of the linear controller are limited in the vicinity of the PPM. This constraint affects system performance since the operating point varies with unexpected and inevitable environmental disturbances. To solve this issue, the working method described in the literature [7, 8] uses a sliding regulator (SMC) to control the inductance or capacitor input current of the boost converter associated with the GPV module, thus ensuring the overall stability of the system at all operating points. The solution proposed in this paper considers multiple cascade controllers as follows: The P\&O MPPT algorithm is used with PI controller to provide the reference to the SMC which generate the MOSFET activation signal.However, the design of these three controllers is done separately, which complicates the perfect control of the system. Incorrect choice of P\&O step size and execution period may result in unstable system operation. And cannot guarantee the same performance over the entire operating range, as the PI controller requires a linearized model of the system around the PPM. In fact, incorrect design of any such PI controller has the potential to make the P\&O unstable.

Based on these previous works and considerations, and to remedy undesirable effects on the output power of the GPV and to extract its maximum power an adaptation stage between the GPV and the load is used, which is usually a DC-DC converter, The input of the DC/DC converter part is formed by the PV generator and the output is connected to variable load. A control system changes the duty cycle and implicitly the input impedance of the converter until the system reaches the MPP Figure 1. The SMC combined with INCC aimed at performing a fast MPPT action on PV systems using a cascade control. This approach avoids the use of linearized models to provide global stability in all the operation range. In such a way, a compact design is achived also reduces the system cost and complexity. The sliding mode control has widely proved its effectiveness through reported theoretical studies. The principal objective consists that the dynamic of the system under control is forced to follow exactly the required response. The benefit of such control and what makes it so interesting is its robustness against system disturbances and uncertainties [9, 10]. In this paper, the interest was focused on the use of an integral PWM-based SMC in the PV system to maximize the energy generated by the GPV and to improve the stability of the system [11].

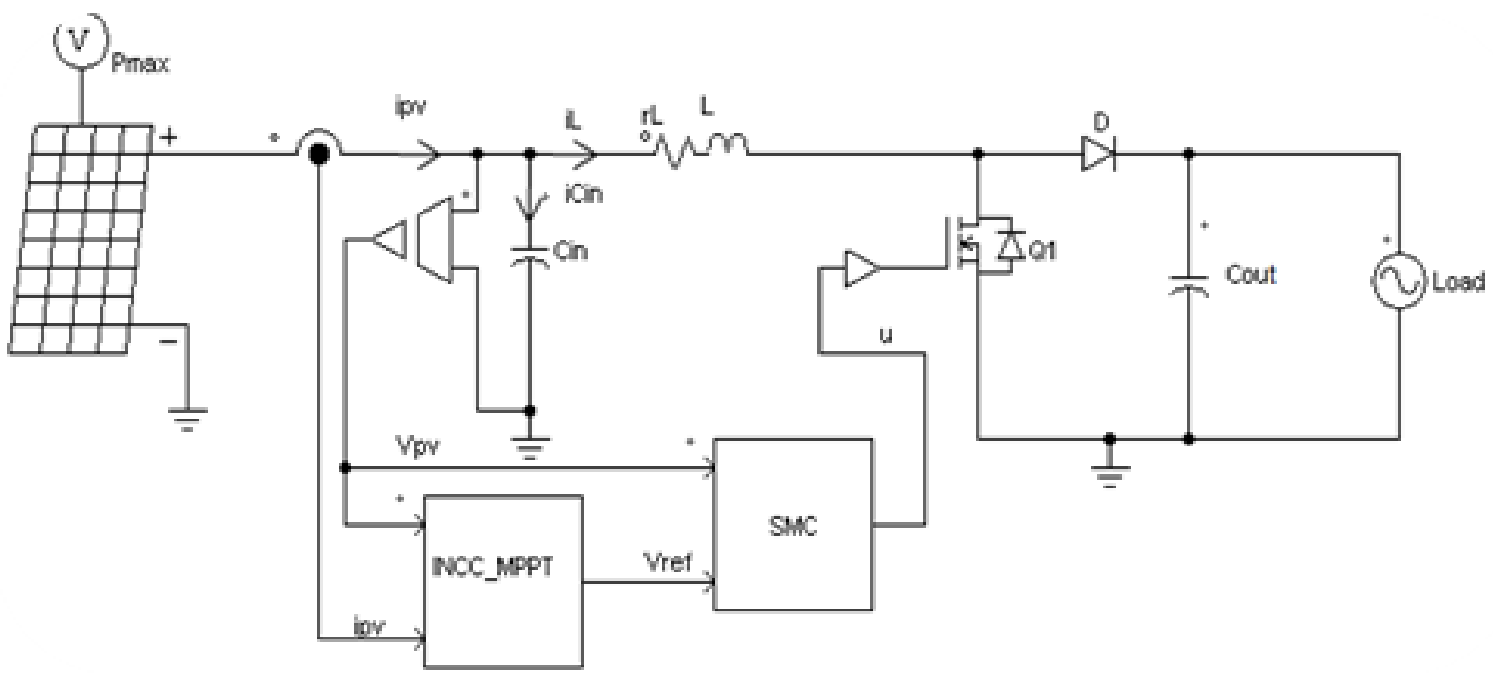

Figure 1. Circuital scheme of the sliding mode controller (SMC) loop

The sliding mode control is applied to follow the maximum power of the photovoltaic system [12]. Among the advantages of this control are high precision, good stability, simplicity, invariance, robustness, etc. $[13,14]$, making it particularly suitable for systems with imprecise models. Often, it is preferable to specify the dynamics of the system during the convergence mode. In this case, the controller structure has two parts, one representing the dynamics during the sliding mode and the other representing the dynamics of the discontinuous system during the convergence mode. The paper is organized as follows: Sections 2.1 
and 2.2 introduces an overview of the photovoltaic generator and the INCC MPPT algorithm, respectively. Then Section 2.3 introduces the non-linear mathematical model representing the GPV and the boost converter. Section 2.4 presents the proposed sliding surface and integral sliding mode controller structure, and derivation of the existence conditions. Numerical simulations using PSIM under various conditions are presented in section 3. Experimental results are represented in 4 illustrate the validity and efficiency of the proposed integral sliding mode controllers compared to the PI strategy. Finally, conclusions are given in the last section.

\section{PHOTOVOLTAIC SYSTEM}

\subsection{Generator photovoltaic GPV}

In literature, several mathematical models describe the operation and behavior of the photovoltaic generator. These models differ in the calculation procedure, accuracy and the number of parameters involved in the calculation of the current-voltage characteristics [15]. One diode model is the most popular. Its equivalent circuit is a p-n junction and when it's illuminated it has the particularity of being able to function as a generator, producing a short-circuit current proportional to the illumination. The equivalent electrical design of a junction is shown in the Figure 2, where the $R_{s h}$ and $R_{s}$ are respectively the parallel and series resistors which represent the losses [16].

The energy source generates the short circuit current Iph, which is mainly dependent on solar radiation. A diode conducts the reverse saturation current $\mathrm{Id}$. The current $\mathrm{I}_{\mathrm{pv}}$ supplying the load is defined by the difference between Id and $I_{p h}, I_{R s h}$. The characteristic $I_{p v}\left(V_{p v}\right)$ of this model is given by the following equations:

$$
\mathrm{I}_{\mathrm{pv}}=\mathrm{I}_{\mathrm{ph}}-\mathrm{I}_{\mathrm{d}}-\mathrm{I}_{\mathrm{Rsh}}
$$

The output current-voltage (I-V) characteristics can be calculated by using the following equation:

$$
I_{P V}=N_{P} I_{S C}-N_{P}\left(E^{\frac{V_{P V}}{N_{S} V_{T}^{A}}+\frac{R_{S} I_{P V}}{N_{S} V_{T^{A}}}}-1\right)-\frac{V_{P V}}{R_{S H}}-\frac{R_{S}}{R_{S H}} I_{P V}
$$

$I_{s c}$ : short-circuit current of PV cell, $R_{s h}$ : Shunt Resistor, $R_{s}$ : resistor series, $I_{d}$ is the reverse saturation current of the diode. $\mathrm{V}_{\mathrm{T}}$ is the thermal voltage; it depends exclusively on the temperature. $\mathrm{N}_{\mathrm{s}}$ number of series cell, $\mathrm{N}_{\mathrm{p}}$ number of parallel cell. To simplify the previous model, an equivalent Thevenin circuit can be derived by using linearization [17], as shown in Figure 3.

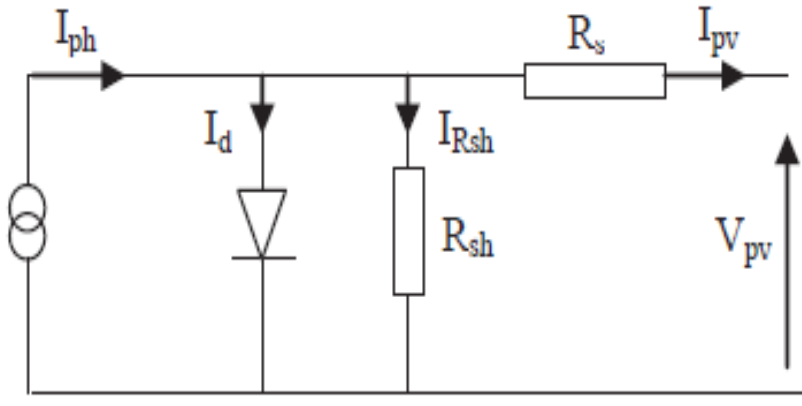

Figure 2. PV cell equivalent circuit

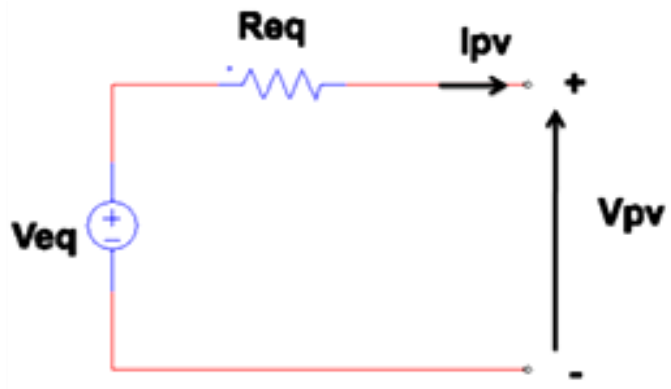

Figure 3. Thevenin model of PV

Where $R_{e q}=\frac{-1}{g}\left(g=\left.\frac{d i_{p v}}{d v_{p v}}\right|_{\substack{i_{p v}=I_{m p} \\ v_{p v}=V_{m p}}}\right.$ is the derivative of the non-linear function ipv vs vpv at the operating MPP point and $V_{\text {eq }}=V_{m p}-\frac{I_{m p}}{g}$ is the equivalent Thevenin voltage. The SCHOTT POLY 240 polycrystalline photovoltaic module is used to analyze and validate the MPPT algorithm, the electrical characteristics are shown in the Table 1 [18]. 


\begin{tabular}{lr} 
Table 1. Electrical characteristics of PV module \\
\hline Nominal Power [Wp] Pmpp & $\geq 240$ \\
Voltage at Nominal Power [V] & 30.4 \\
Vmpp & \\
Current at Nominal Power [A] Impp & 7.90 \\
Open-Circuit Voltage [V] Voc $\quad$ Vo & 37.3 \\
Short-Circuit Current [A] Isc & 8.47 \\
\hline \multicolumn{2}{l}{ STC $\left(1000 \mathrm{~W} / \mathrm{m} 2\right.$, AM 1.5 cell temperature $25^{\circ} \mathrm{C}$}
\end{tabular}

\subsection{Incremental conductance design}

The Incremental Conductance Algorithm (INCC) takes its base on the fact that the maximum power point (MPP) is only reached if $\frac{\mathrm{dP}_{\mathrm{PV}}}{\mathrm{dV}_{\mathrm{PV}}}$ is zero, if the derivative is negative the operation point is on the right of the maximum, when it is positive the operation point is on the right [19, 20]. The MPP can therefore be maintained by comparing the instantaneous conductance $(\mathrm{Gci}=\mathrm{I} / \mathrm{V})$ with the increment of the conductance $(\Delta \mathrm{Gci}=\Delta \mathrm{I} / \Delta \mathrm{V})$, as shown in the flowchart in Figure 4. $\mathrm{V}_{\text {ref }}$ corresponds to the reference voltage for which the PV panel is forced to start operating. In the MPP, $V_{\text {ref }}=V_{\text {MPP }}$. Oncewereach the MPP, we maintain the corresponding operating point. However if a change in $\mathrm{I}_{\mathrm{pv}}$ is noted, wich is related to a change in the atmospheric conditions and therefore a change of the operating point corresponding to the MPP. The algorithm varies $\mathrm{V}_{\text {ref }}$ upwards or downwards depending on the new MPP. The increment's size determines how quickly the MPP can be tracked. A quick tracking can be obtained with a larger increment, but the system could not operate exactly at the MPP and oscillates around it. As with the P\&O method, we have to make a choice between high speed and high precision, therefore we have to find the best compromise between these two variables. We can improve this method by neering the operating point to the MPP in the first step, and using afterwards the second controller to accurately track the MPP. Others method are commonly used in the literature, it consist of using a controller to keep the $\mathrm{V}_{\mathrm{pv}}$ voltage operate at Vmpp and ensure the stability of system $[21,22]$.

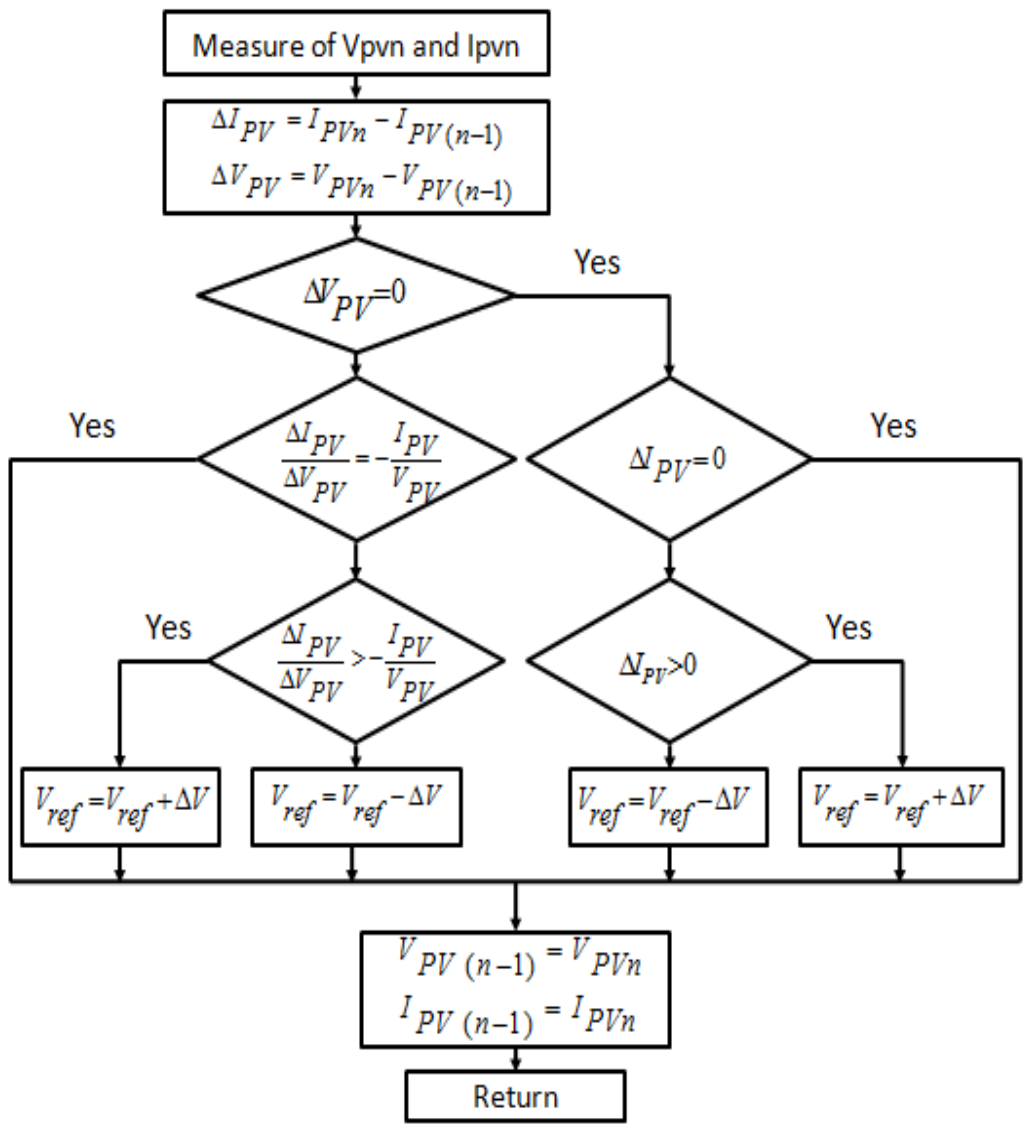

Figure 4. Flowcharte of incremental conductance algorithm 


\subsection{Boost converter}

Despite the choice of the MPPT algorithm, a DCDC converter is necessary to interface the GPV and the load to lead the GPV to the MPPT. The classical solution described in the published literature [23] consists of a DC/DC converter with an MPPT controller and a regulated DC/AC converter to inject energy into the network and adjust the DC bus voltage. The overall system is shown in Figure 5. This solution is widely adopted as it allows simultaneous monitoring of the MPP and power factor correction [24]. The DC/DC converter with an MPPT controller allows the GPV bus voltage to be regulated as a function of the MPP. Besides, the DC/DC converter selected in this architecture generally uses a step-up converter to adapt the input voltage to a high voltage required by conventional grid-connected inverters [25]. Thus, the efficiency and stability of the photovoltaic system are guaranteed..

Figure 6 represents the PV system's electrical circuit without losses. The dynamic equations are defined to represent the system in the state space where the state variables are the inductor current and the voltage at input capacitor, while the input of the converter is the duty cycle, the Thevenin equivalent circuit model represents the $\mathrm{PV}$, and the output voltage of the boost converter corresponds to $\mathrm{V}_{0}$, the inductor current is iL, and the duty cycle is d. In addition, the inductance of the step-up converter is designed to operate in continuous conduction mode $\operatorname{CCM}[26,27]$ since the discontinuous conduction mode (DCM) is not recommended for the solar system and thus causes a large voltage ripple and oscillations around the MPP [28], reducing that way the effective power injected into the grid.

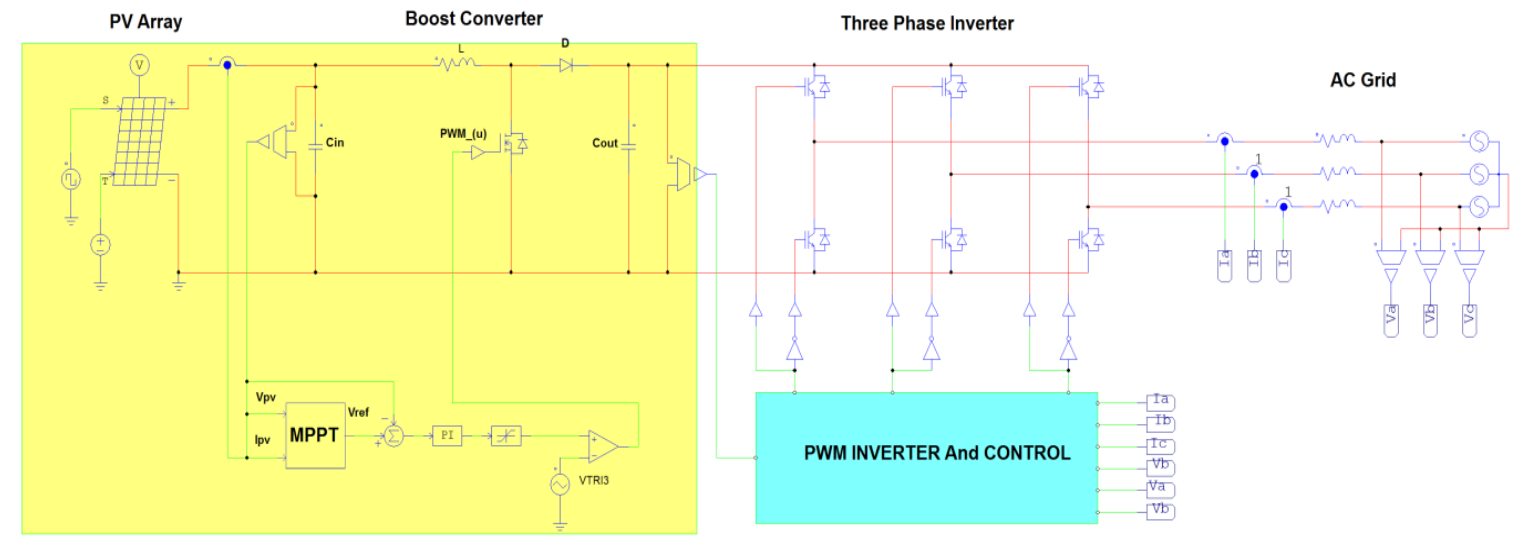

Figure 5. Typical architecture of a grid connected PV system

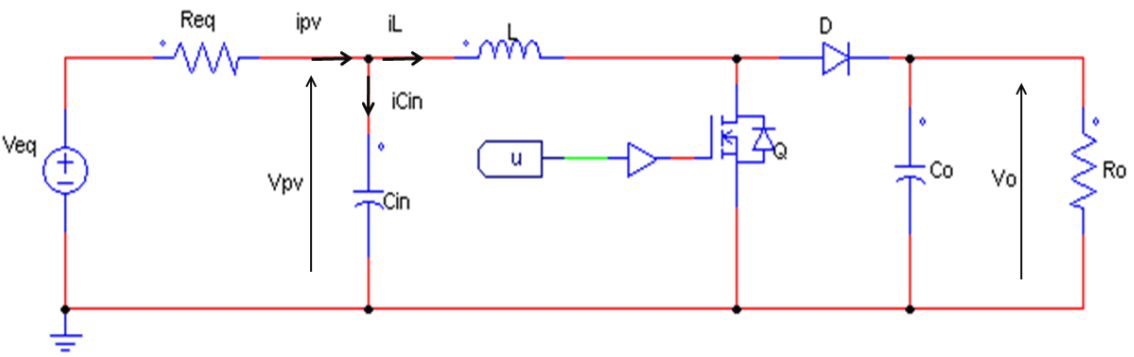

Figure 6. Thevenin model of GPV in cascade with boost converter

All averaging state equations over a switching period are given in the following set.

$$
\begin{aligned}
& V_{e q}-R_{e q} i_{p v}-v_{p v}=0 \\
& i_{p v}=i_{C i n}+i_{L} \\
& L \frac{d i_{L}}{d t}=v_{p v}-(1-u) \mathrm{V}_{\mathrm{o}}
\end{aligned}
$$




$$
\begin{aligned}
& C \frac{d v_{C o}}{d t}=(1-u) i_{L}-\frac{V_{O}}{R o} \\
& \frac{d v_{p v}}{d t}=\frac{i_{p v}}{\operatorname{Cin}}-\frac{i_{L}}{\operatorname{Cin}}
\end{aligned}
$$

Control to input voltage transfer function:

$$
\frac{v_{p v}(s)}{d}=\frac{-R_{e q} V_{o}}{R_{e q}+L s+C_{i n} R_{e q} L s^{2}}
$$

To validate the MPPT approach we consider a commercial panel SCHOTT POLY 240 which the boost converter follows the feature: $\mathrm{Cin}=1000 \mathrm{uF}, \mathrm{L}=270 \mathrm{uH}, \mathrm{Co}=100 \mathrm{uF}, \mathrm{Vo}=70 \mathrm{~V}$ with a switching frequency at $50 \mathrm{kHz}$. The PI controller'sdesign was based on plant damping ratio and undamped natural frequency.Wefixed the damping ratio at 0.7 , and wesettledthe time under $80 \mathrm{~ms}$ and the error at steady state under 5\%, belowwegive the PI controler'stransfer function:

$$
G_{P I}(s)=0.001+\frac{0.71}{s}
$$

\subsection{Sliding mode controller design}

In recent decades the sliding mode control has expanded considerably. This phenomenon is mostly caused by the fast and finite time convergence property of errors, as well as the high robustness against modeling errors and some types of external disturbances $[29,30]$. The switching functions of state variables, on which is based this non-linear control, are used to create a sliding surface or hypersurface, in the perspective of making the dynamics of system to reach a given sliding surface and remain there until equilibrium is achieved, Figure 7. This dynamics becomes then insensitive to disturbances may they be external or parametric as long as the sliding control's conditions are secured [31].

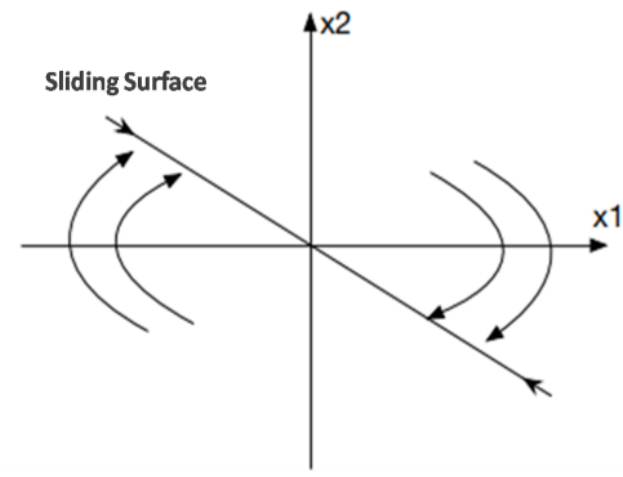

Figure 7. Illustration of sliding surface convergence

Our focus in this section is the application of SMC control to a boost converter operating in CCM. The solution proposed in this work is to consider two cascade controllers as follows: the INCC control which is designed to provide a reference which is proportional to the optimal power $\mathrm{P}_{\mathrm{MPP}}$ of the photovoltaic generator, as well as the SMC controller which is in charge of th GPV voltage regulation. The controller under study is a second-order proportional-integral-derivative (PID) SM voltage-mode controller. It takes into account an additional voltage error integral term in the control algorithm to reduce the steady-state error of the practical SM-controlled system. The applications of this system commonly known as integral SM control has attracted many recent interests such as their use in power converters $[32,33]$. The control variable $\mathrm{x}$ for the PID SMC can be enunciated in the form below:

$$
x=\left[\begin{array}{l}
x_{1} \\
x_{2} \\
x_{3}
\end{array}\right]=\left[\begin{array}{c}
V_{\text {ref }}-\beta V_{P V} \\
\frac{d}{d x}\left(V_{\text {ref }}-\beta V_{P V}\right) \\
\int\left(V_{\text {ref }}-\beta V_{P V}\right)
\end{array}\right]
$$


where $\mathrm{x}_{1}, \mathrm{x}_{2}$, and $\mathrm{x}_{3}$ are respectively the voltage error, the voltage error dynamics (or the rate of variation of voltage error), and the integral of voltage error. Next step is substitution of the converter behavioral models under CCM into (10), and time differentiation of this last equation produce the state-space descriptions required for the controller design of the GPV and boost converters.

$$
\left[\begin{array}{l}
\dot{\mathrm{x}}_{1} \\
\dot{\mathrm{x}}_{2} \\
\dot{\mathrm{x}}_{3}
\end{array}\right]=\left[\begin{array}{ccc}
0 & 1 & 0 \\
-\frac{1}{\operatorname{Cin} . \mathrm{L}} & -\frac{1}{\text { Req.Cin }} & 0 \\
1 & 0 & 0
\end{array}\right] \cdot\left[\begin{array}{l}
\mathrm{x}_{1} \\
\mathrm{x}_{2} \\
\mathrm{x}_{3}
\end{array}\right]+\left[\begin{array}{c}
0 \\
-\frac{\beta \cdot \mathrm{Vb}}{\operatorname{Cin} . \mathrm{L}} \\
0
\end{array}\right] \cdot \mathrm{U}+\left[\begin{array}{c}
0 \\
\text { Vref } \\
\text { Cin. } \mathrm{L}
\end{array}\right]
$$

The standard form of the state space equation gives:

$$
\dot{\mathrm{x}}=\mathrm{Ax}+\mathrm{Bv}+\mathrm{D}
$$

After the state-space descriptions are obtained, designing the controller is the next step. For systems like those, it is recommended to have a general SM control law that adopts a switching function such as:

$$
\mathrm{u}=\left\{\begin{array}{l}
1 \text { when } \mathrm{S}>0 \\
0 \text { when } \mathrm{S}<0
\end{array}\right.
$$

where $S$, that can be expressed by the equation bellow, represents the instantaneous state trajectory:

$$
\mathrm{S}=\alpha_{1} \mathrm{x}_{1}+\alpha_{2} \mathrm{x}_{2}+\alpha_{3} \mathrm{x}_{3}=\mathrm{J}^{\mathrm{T}} \mathrm{x}
$$

With $J^{\mathrm{T}}=\left[\alpha_{1} \alpha_{2} \alpha_{3}\right] ; \alpha_{1}, \alpha_{2}, \alpha_{3}$ representing the sliding coefficients.

\subsubsection{Derivation of existence conditions}

The next important issue of sliding mode control after switching surface design is guaranteeing the existence of a sliding mode. A suitable condition exists in the literature; it is called the reachability condition and is written as follows [34].

$$
\lim _{S \rightarrow 0} S \dot{S}<0
$$

Must be satisfied. This can be expressed as

$$
\begin{aligned}
& \left\{\begin{array}{l}
\dot{\mathrm{S}}_{\mathrm{S} \rightarrow 0^{+}}=\mathrm{J}^{\mathrm{T}} \mathrm{Ax}+\mathrm{J}^{\mathrm{T}} \mathrm{Bv}_{\mathrm{S} \rightarrow 0^{+}}+\mathrm{J}^{\mathrm{T}} \mathrm{D}<0 \\
\dot{\mathrm{S}}_{\mathrm{S} \rightarrow 0^{-}}=\mathrm{J}^{\mathrm{T}} \mathrm{Ax}+\mathrm{J}^{\mathrm{T}} \mathrm{Bv}_{\mathrm{S} \rightarrow 0^{-}}+\mathrm{J}^{\mathrm{T}} \mathrm{D}>0
\end{array}\right. \\
& 0<\mathrm{C}_{\mathrm{in}} \mathrm{L}\left(\frac{\alpha_{3}}{\alpha_{2}}-\frac{1}{\mathrm{C}_{\mathrm{in}} \mathrm{L}}\right)\left(\mathrm{V}_{\mathrm{ref}}-\beta \mathrm{V}_{\mathrm{PV}}\right)-\beta \mathrm{L}\left(\frac{\alpha_{2}}{\alpha_{1}}-\frac{1}{\mathrm{C}_{\mathrm{in}} \mathrm{L}}\right)\left(\mathrm{i}_{\mathrm{PV}}-\mathrm{i}_{\mathrm{L}}\right)<\beta \mathrm{V}_{\mathrm{O}}-\mathrm{V}_{\text {ref }}
\end{aligned}
$$

This controller's derivation process can be summarized in two steps. Firstly, the formulation of the equivalent control signal $u_{e q}$ which is a smooth function of the discrete input function $u$, using the invariance conditions by setting the time differentiation of (16) as $\dot{S}=0$. Secondly, the translation of the equivalent control function to the instantaneous duty ratio $\mathrm{d}$ of the pulse-width modulator

$$
\tilde{\mathrm{u}}_{\mathrm{eq}}=-\left[\mathrm{J}^{\mathrm{T}} \mathrm{B}\right]^{-1} \mathrm{~J}^{\mathrm{T}}[\mathrm{Ax}+\mathrm{D}]
$$

where $0<\tilde{\mathrm{u}}_{\mathrm{eq}}<1$

Since $\mathrm{u}=1-\tilde{\mathrm{u}}$, which also applies $\mathrm{u}_{\mathrm{eq}}=1-\tilde{\mathrm{u}}_{\mathrm{eq}}$, the control law can be written as:

$$
0<u_{\text {eq }}=\frac{\beta V_{0}+C_{i n} L\left(\frac{\alpha_{3}}{\alpha_{2}}-\frac{1}{C_{i n}}\right)\left(V_{\text {ref }}-\beta V_{P V}\right)-\beta L\left(\frac{\alpha_{2}}{\alpha_{1}}-\frac{1}{C_{i n} L}\right)\left(i_{P V}-i_{L}\right)+V_{\text {ref }}}{\beta V_{o}}<1
$$

Finally, translating the equivalent control function (19) to the duty ratio d, where $0<d=\mathrm{v}_{\mathrm{c}}<1$, gives the following relationships for the control signal $v_{c}$ and ramp signal $\hat{v}_{\text {ramp }}=1$ for the practical implementation of the PWM-based SM controller: 


$$
\begin{aligned}
& \mathrm{v}_{\mathrm{c}}=\mathrm{u}_{\mathrm{eq}}=\mathrm{Kp} 1\left(\mathrm{~V}_{\mathrm{ref}}-\beta \mathrm{V}_{\mathrm{PV}}\right)-\mathrm{Kp} 2\left(\mathrm{i}_{\mathrm{PV}}-\mathrm{i}_{\mathrm{L}}\right)+\frac{\beta \mathrm{V}_{\mathrm{o}}+\mathrm{V}_{\mathrm{ref}}}{\beta \mathrm{V}_{\mathrm{o}}} \\
& \text { and } \hat{\mathrm{v}}_{\mathrm{ramp}}=1
\end{aligned}
$$$$
\text { with } \mathrm{Kp} 1=\frac{\mathrm{C}_{\mathrm{in}} \mathrm{L}\left(\frac{\alpha_{3}}{\alpha_{2}}-\frac{1}{\mathrm{C}_{\mathrm{in}} \mathrm{L}}\right)}{\beta \mathrm{V}_{\mathrm{o}}} \text { and } \mathrm{Kp} 2=\frac{\beta \mathrm{L}\left(\frac{\alpha_{2}}{\alpha_{1}}-\frac{1}{\mathrm{C}_{\mathrm{in}} \mathrm{L}}\right)}{\beta \mathrm{V}_{\mathrm{o}}}
$$

Inequality (15) doesn't reveal any details about the choice of SMC coefficient, but only provides general information about SMC existence. The choice of sliding coefficients according to the desired dynamic properties is largely detailed in previous literature [34], using Ackermann's formula for the design of static controllers. In this way, the stability condition of the system is automatically satisfied. In addition, the resolution of equation $\mathrm{S}=0$, which is proportional to the SMC coefficients, results in a second-order system with three possible response types:under-damping, critical damping, and over-damping.

$$
\frac{\alpha_{1}}{\alpha_{2}}=\frac{10}{T_{s}}
$$

and the desired damping ration can be set using

$$
\frac{\alpha_{3}}{\alpha_{2}}=\frac{25}{\varepsilon^{2} \mathrm{~T}_{\mathrm{s}}^{2}}
$$

where $\varepsilon=\sqrt{\frac{\left[\ln \left(\frac{\mathrm{Mp}}{100}\right)\right]^{2}}{\pi^{2}+\left[\ln \left(\frac{\mathrm{Mp}}{100}\right)\right]^{2}}}$

\section{SIMULATION RESULTS AND DISCUSSION}

The purpose of this paragraph is to present the simulation results of the sliding mode control (SMC) technique and to compare it with the INCC asscociatd with classical PI controller. The simulation was performed using PSIM software as shown in the Figure 8. It consists of varying the three parameters influencing the PV conversion chains, namely climatic conditions G, temperature $\mathrm{T}$ and load $\mathrm{R}$. The results obtained are presented in Figures 9 and 10 for duration of 1 second. For the test of each parameter, two parameters are kept constant and the third parameter is varied by a sudden change twice $0.3 \mathrm{~s}$ and $0.6 \mathrm{~s}$ (step profile). Each figure shows a comparison of PV power between the INCC+ SMC and INCC+PI methods. A zoom is made in two places, the first at the start of the profile to illustrate the response time and the second to show the oscillations around the PPM.

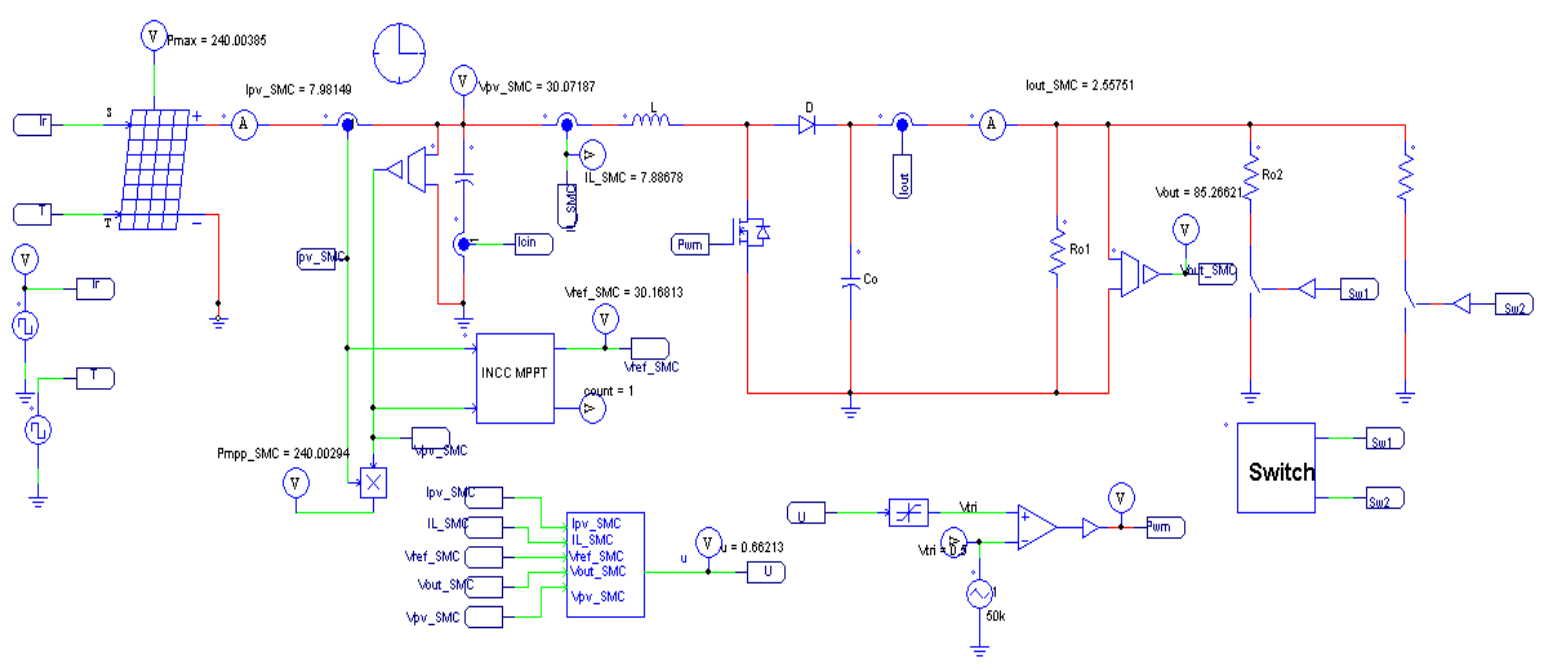

Figure 8. Circuital scheme for simulation of SMC loop in PSIM 
Several tests have been performed to evaluate the performance of SMC for MPP monitoring. First, the control of the SMC is tested by varying the irradiance while fixing the load to $100 \Omega$ and temperature at $25^{\circ} \mathrm{C}$. The corresponding simulations compared with PI controller results are shown in Figure 9. The low tracking speed of the conventional INCC algorithm are confirmed by the results with PI controller under irradiation changes (about $0.32 \mathrm{~ms}$ ) with significant PV voltage fluctuation around the reference voltage VMP in steady-state. In the opposite, by using the sliding control scheme as proposed (about 0.16ms) a high tracking performance was exhibited. Also, when the irradiation changes without overshoots an instantaneous effect on the PV voltage is displayed with less fluctuation around $\mathrm{V}_{\mathrm{MPP}}$, as shown in Figure 9(b) (blue curve). Moreover, Figure 9(a) compares the proposed control scheme and the conventional INCC+PI MPPT and it shows the improvement in the extracted PV power using the PI controller. The results also confirm that the optimal current is significantly affected by the sudden change in illumination Figure 9(c), while the optimal voltage is less affected Figure 9(b).

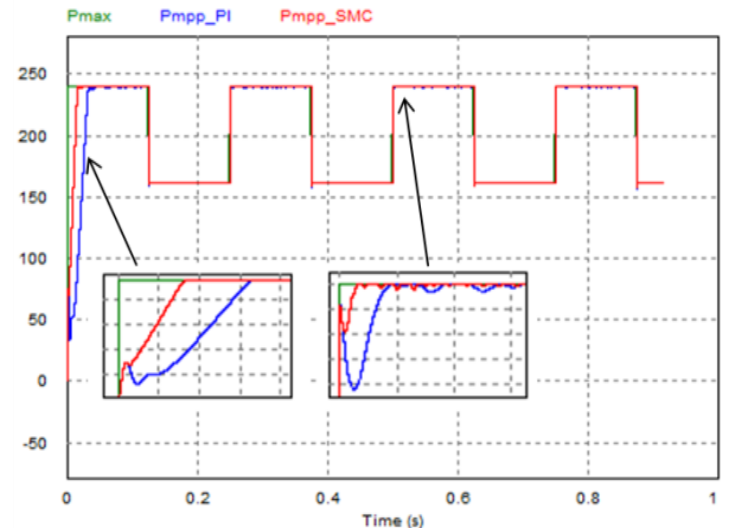

(a)

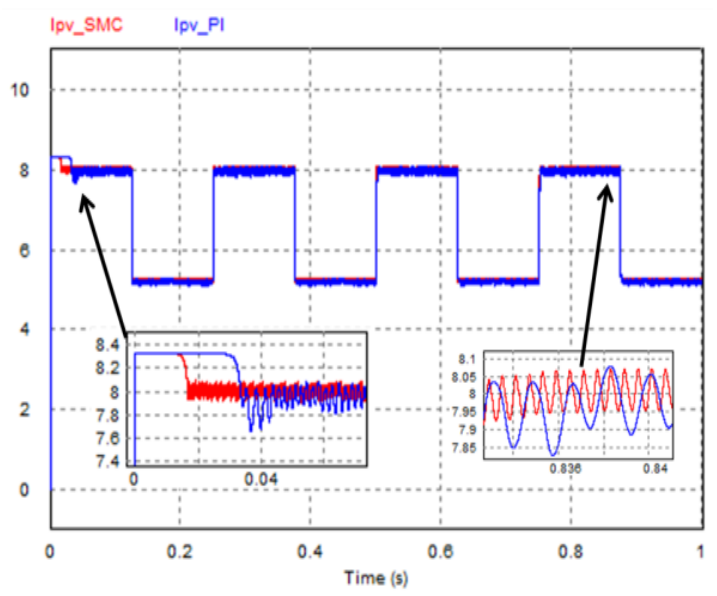

(c)

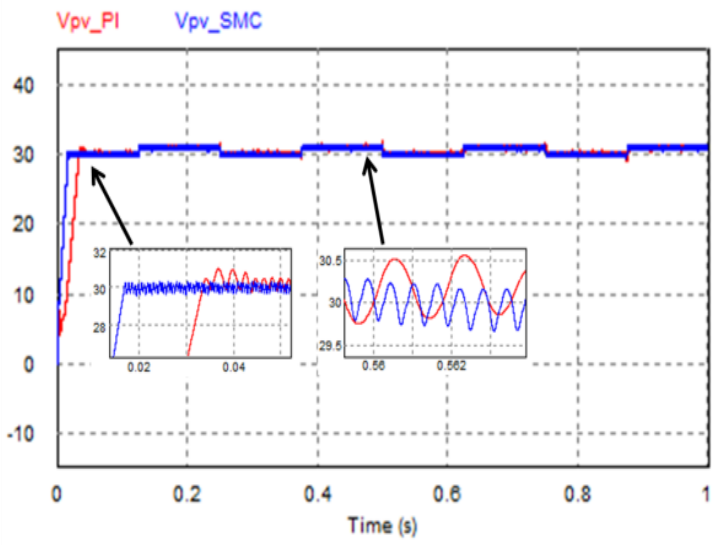

(b)

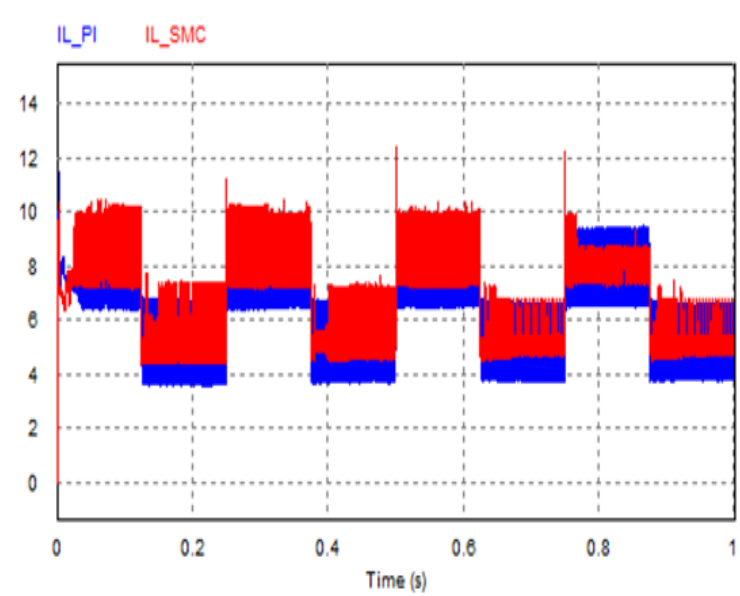

(d)

Figure 9. Comparison between SMC and PI controller under variation of irradiance $(650 \mathrm{~W} / \mathrm{m} 2$ to 1000W/m2); (a) GPV power characteristics, (b) GPV voltage, (c) GPV current, (d) Inductance current

A second test is done for the PV system under a constant irradiation of $1000 \mathrm{~W} / \mathrm{m} 2$. But this time, the temperature and the load are changed from $100 \Omega$ to $50 \Omega$ and to $25 \Omega$ Figure 10 presents the simulation results with these conditions. This time the difference in response time is almost the same, it is about 0.16 $\mathrm{ms}$. Also, the SMC corrects a little the trajectory of the PPM during the transient regimes. In steady state, INCC+PI oscillate around the PPM between $240 \mathrm{~W}$ and 239.82 vs $240 \mathrm{~W}$ and $238.99 \mathrm{~W}$. From these results, it can be said that the sliding mode control reaches steady state in a very short time in the order of milliseconds. And it is not influenced by changing weather conditions or a sudden change in the load, it is faster than the PI controller and without oscillating arount the PPM. 


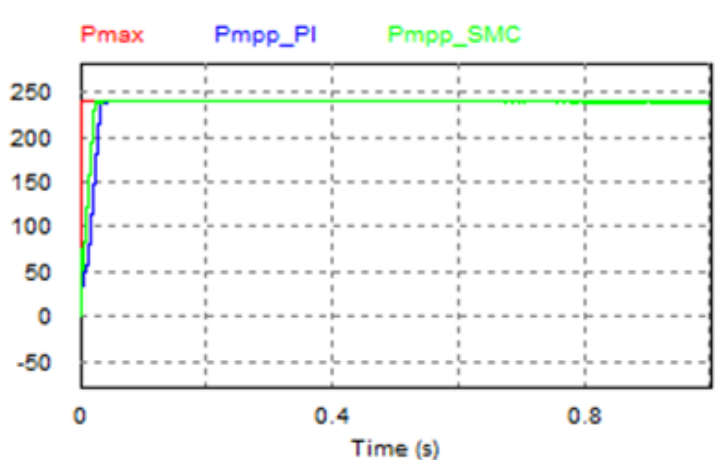

(a)

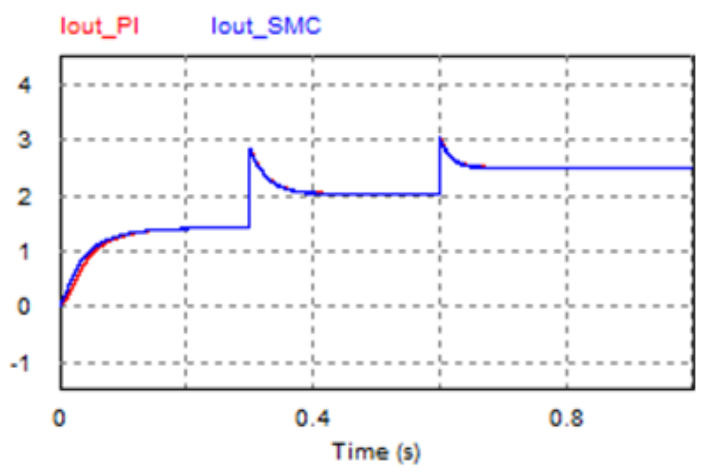

(c)

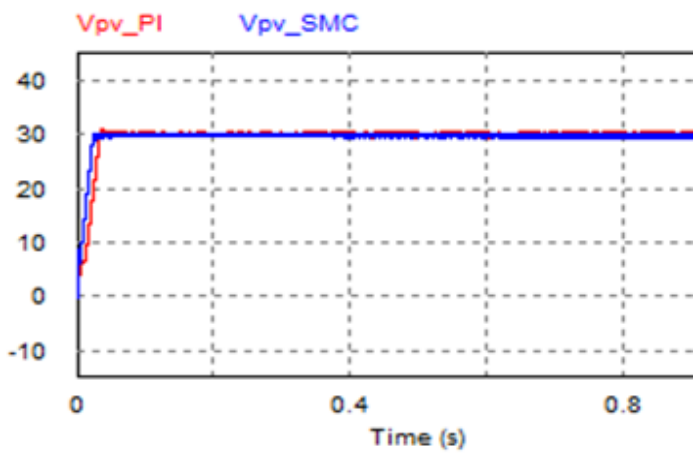

(b)

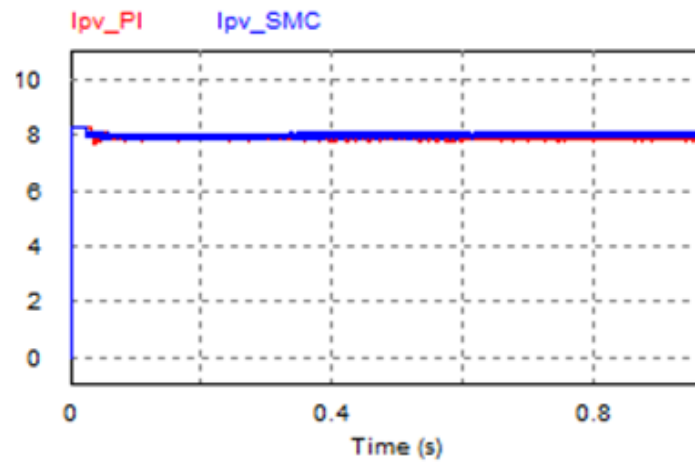

(d)

Figure 10. Comparison between SMC and PI controller under variation of the load and constant irradiation; (a) GPV power characteristics, (b) GPV voltage, (c) GPV current, (b) Inductance current

\section{EXPERIMENTAL TEST}

The Boost converter is used as an adaptive stage between GPV and load, and is used to boost the low PV output voltage to a high-voltage DC bus needed for inverter. The photovoltaic current and the inductor currentare sensed by a Hall effect current sensor ACS711 (-12.5A to +12.5A), the GPV voltage and output voltage of the boost converter are sensed by resistor devider. The four signals are interfaced by STM32F407VG Discovery board through the ADC channels for the control of the DC-DC converter. The STM32F407VG controls the hardware part by using one PWM output for switching the MOSFET transistor (SCH2080KE). The Figure 11 shown the experimental bloc. The strategy of control is implemented in two loop control, one is slow for the Incremental conductance Algorithm $(500 \mathrm{~Hz})$ and the other is fast for SMC and PI voltage control loop with a high frequency PWM $50 \mathrm{kHz}$.

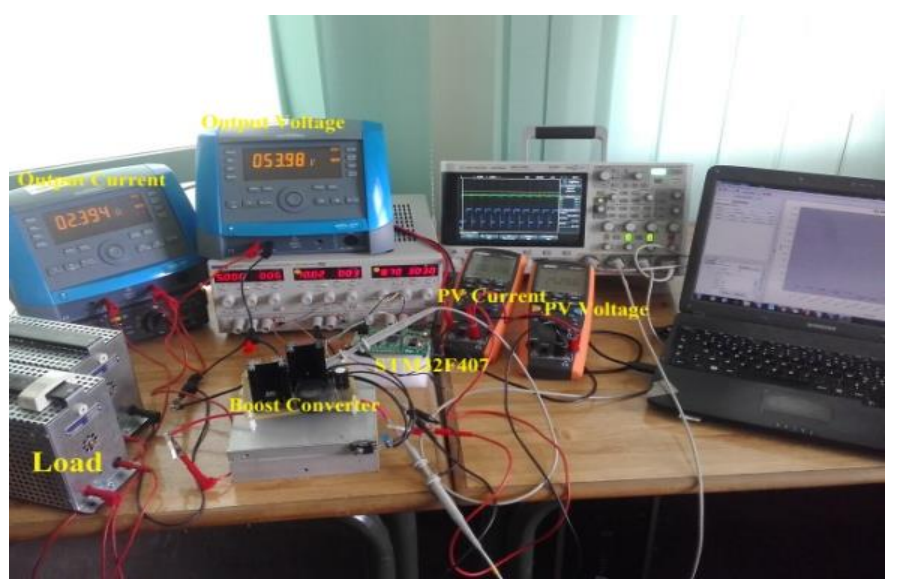

Figure 11. Experimental system bloc 


\subsection{Experimental results and discussion}

In the first, the PV panel is characterized by a variable resistor in real test condition to define the real MPP. In the test condition the PV panel SCHOTT POLY 240 delivers a MPP near at 190W for $\mathrm{Vpv}=24.9 \mathrm{~V}$, and $\mathrm{Ipv}=7.5 \mathrm{~A}$. The result is shown the Figure 12.

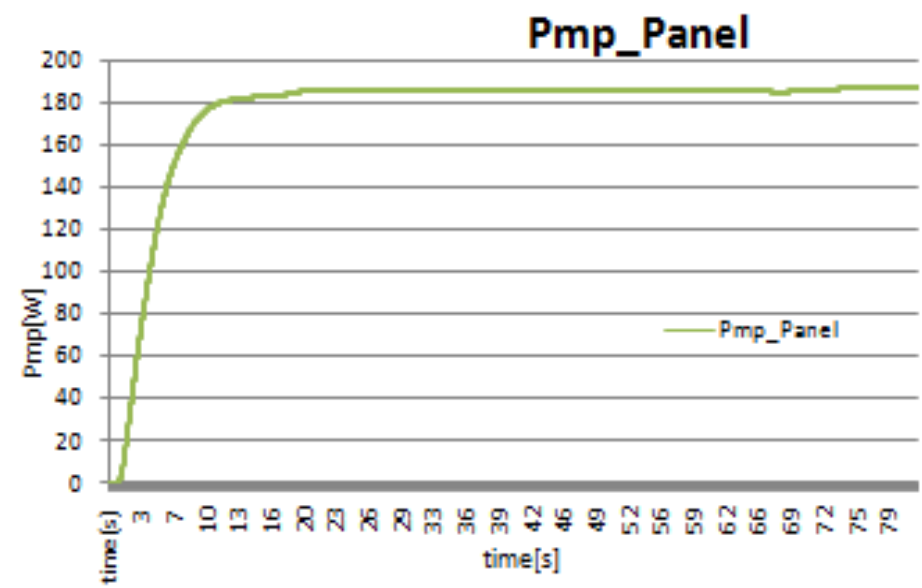

(a)

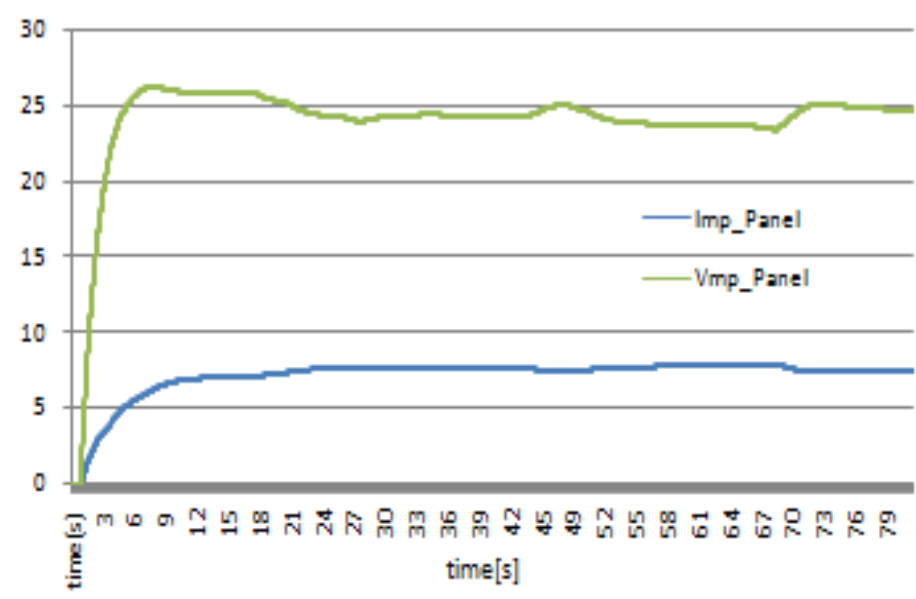

(b)

Figure 12. GPV characterization; (a) PPM of GPV panel, (b) Vmp and Imp of GPV

We capture the feedback signals Ipv and Vpv through the tools STMStudio for STM32F407VG. The Figure 13 (a) and (b) represents the experimental results where the Vpv_SMC( resp Ipv_SMC) is the PV voltage (resp PV current) regulated by SMC control and the Vpv_PI (resp Ipv_PI) is PV voltage (resp PV current) regulated by the PI controller, while The Figure 13(c) and (d) represents the PV power response and the PWM driving signal for the MOSFET.

Furthermore, the analysis of the PV voltage regulation using the conventional PI controller and the proposed PWM-SMC scheme shows the results represented in Figure 13(a). This comparison confirms the tracking superiority of the PWM-SMC scheme compared to the conventional one.When using the conventional PI controller, we can observe that the PV voltage deviates from its refrence and oscillats more around VMP.

Moreover, in the transient time, the undershoot and response time are significantly large. In contrast, tracking the desired reference employing the PWM-SMC is quite accurate.Moreover, the performance improvement by using the proposed control scheme generates a relatively high damped and short response compared to the conventional scheme. In the other hand, Figure 13(b) shows the input PV current response for the two methods: we can see that Ipv current converge in fast time to the Imp compared to the Ipv of the PI controller. 
Figure 13 (c) represents the PV power response for the two controllers. It shows that both the SMC and PI controllers converged at the maximum power pointor aroundit.The dynamic results illustrate the ability of SMC method to converge faster without oscillations in a steady state, and in the same timeextracting the maximum power from photovoltaic panel. In comparison the INCC+PI method have a slower response at the begining with more oscilation around PV voltage.

The STM32F407 discovery boad increased the performance of the MPPT function using an implementation of the Incremental Conductance combined with SMC. The MPPT algorithm extracts maximum power from the photovoltaic panel and delivers it to the DC load regardless of the panel's characteristics. The effect on the panel voltage are shown on the experimental testing : the MPPT algorithm allows maintaining constant power at the panel, maximizing that way the PV output power via adapting load and PV internal impedance.

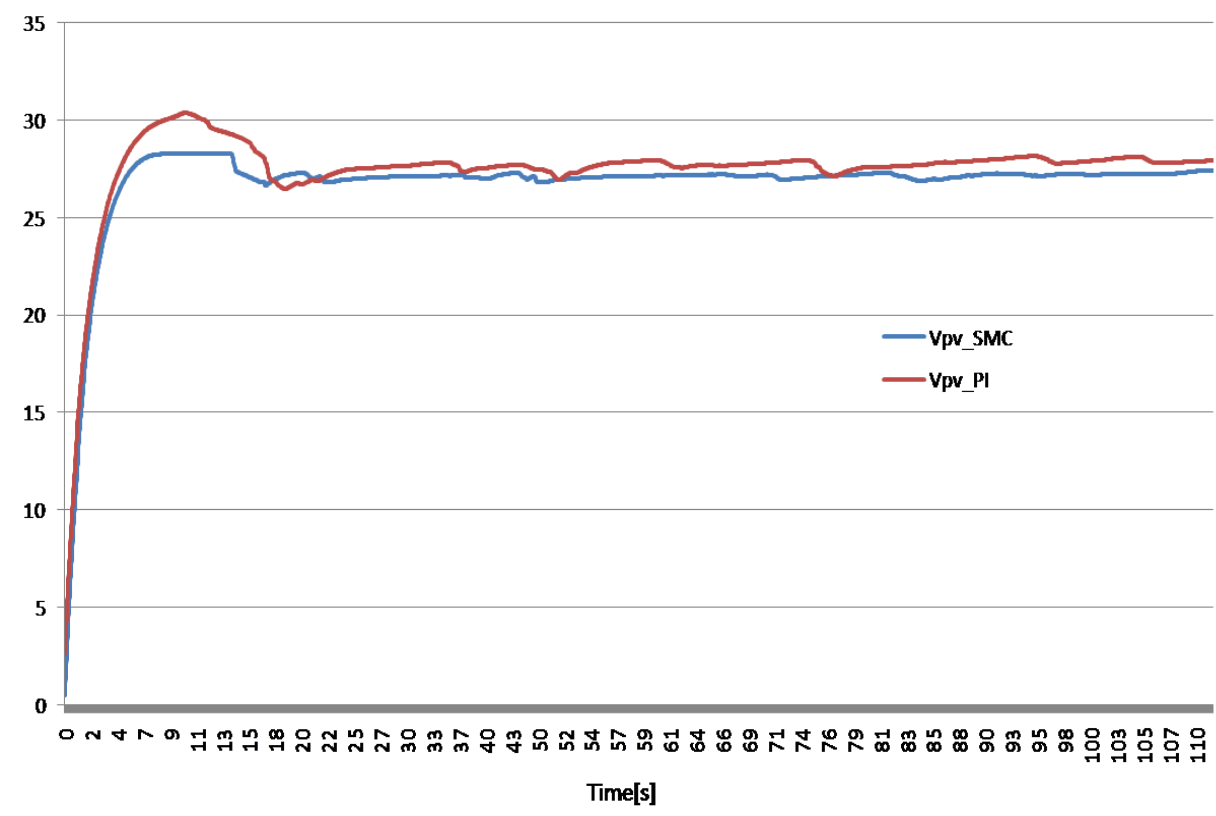

(a)

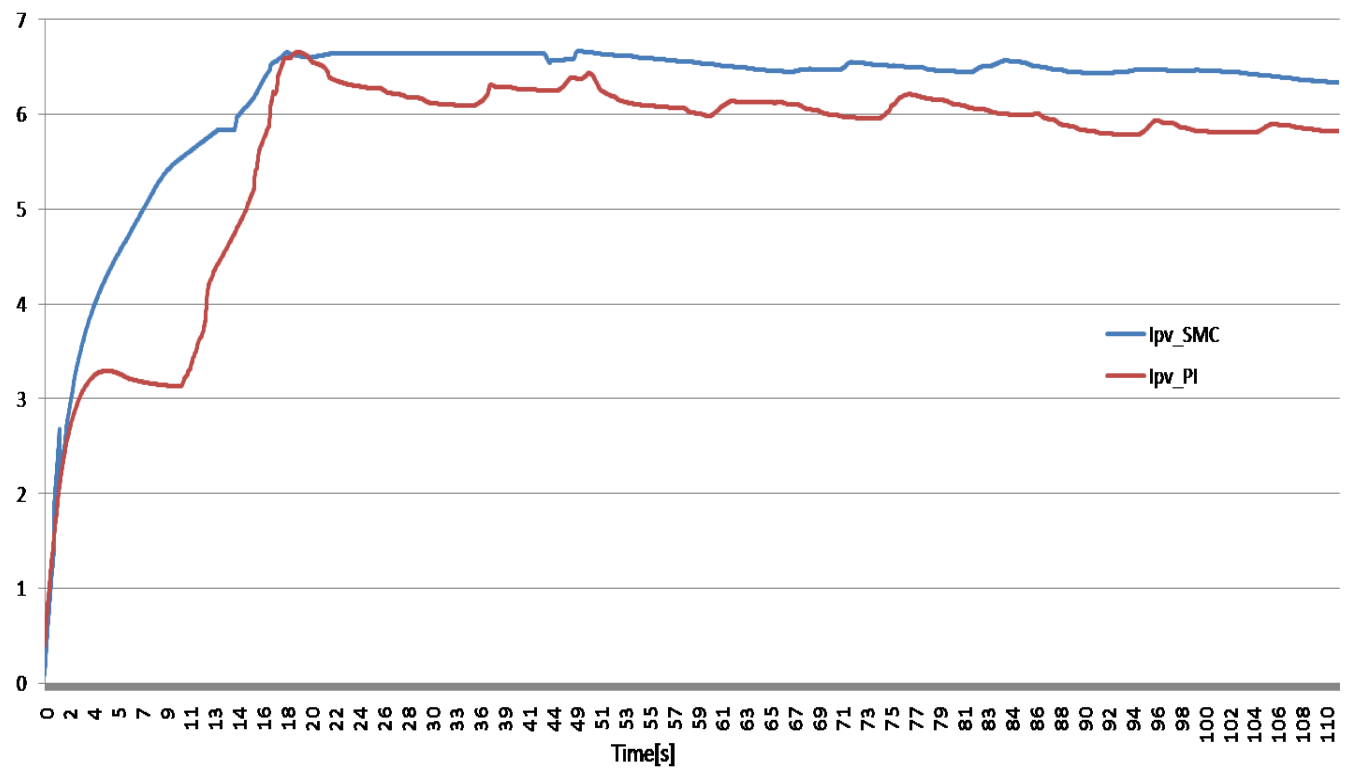

(b)

Figure 13. (a) PV voltage comparison, (b) PV current comparison 


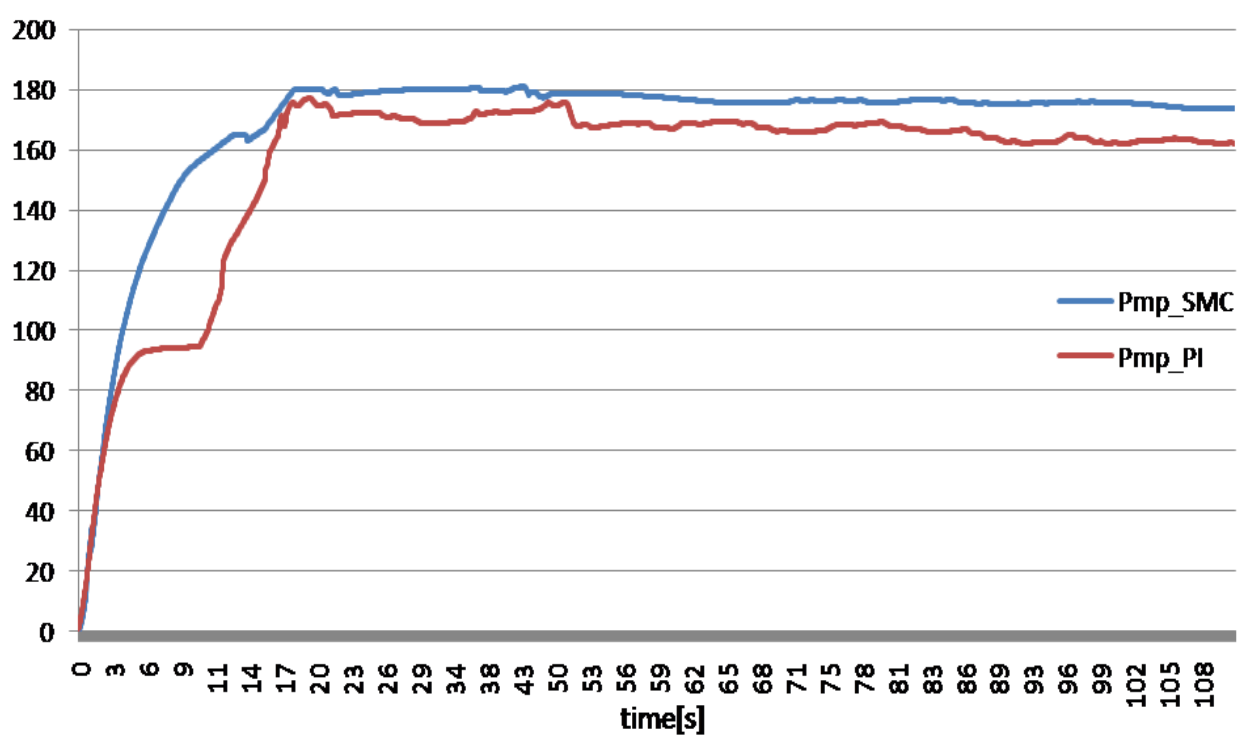

(c)

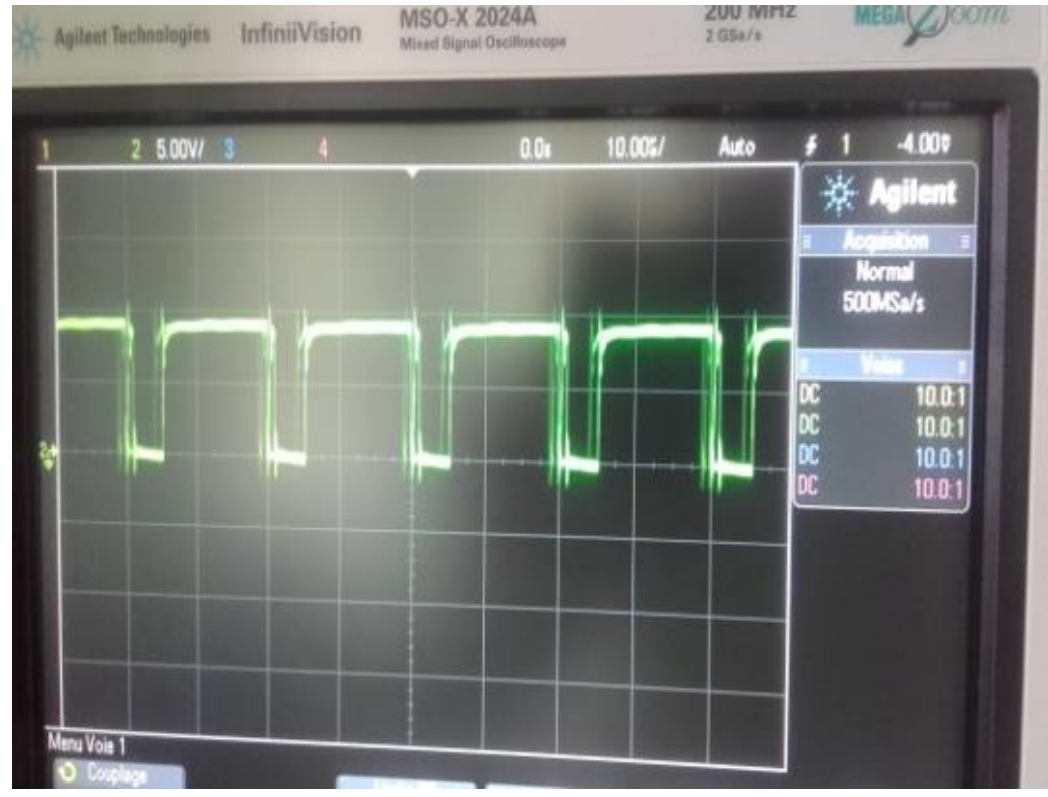

(d)

Figure 13. PV power comparison, (d) PWM driving signal for MOSFET (continue)

\section{CONCLUSIONS}

This paper presented a high-performance control schemeaiming to maximize the transfer of electrical energy from GPV to a two-stage grid-tied PV system. The SMC theory and MPPT controlare the base of the proposed scheme of this control structure which aims to improve the system's performance regardless of the climatic conditions. As it is a two-stage system, the PV power is provided to the grid through a DC-DC boost converter a SMC controller for the boost converter has been proposed for MPP tracking. The results obtained from the simulation confirm the fact that this method is feasable, effective, and improves the performance compared to traditional PI controller. The comparison of the simulation results of the SMC based on PWM and MPPT based PI controller that SMC is able to reach the optimal operating point during a sudden change in solar radiation with high performance even in dynamic load variation and temperature. The system's response to the square profile variation of irradiance proves that the technique reduces trajectory errors in the pursuit of MPP. The validation of the proposed method relies on the experimental test. 


\section{ACKNOWLEDGMENTS}

The authors gratefully acknowledge IRESEN (Moroccan Research Institute for Solar and New Energy) for the financial support of the $6 \mathrm{kVA}$ inverter research project.

\section{REFERENCES}

[1] Farhat, Maissa, Barambones, Oscar, and Sbita, Lassaad, "A new maximum power point method based on a sliding mode approach for solar energy harvesting," Appliedenergy, vol. 185, pp. 1185-1198, 2017.

[2] Farhat, Maissa, Barambones, Oscar, Ramos, Jose A., et al., "Maximum power point tracking controller based on sliding mode approach," Actas de las XXXV Jornadas de Automática, pp. 3-5, 2014.

[3] Zakzouk Ne, Abdelsalam Aka, Helal A, Williams Bw., "Modified variable-step incremental conductance maximum power point tracking technique for photovoltaic systems," In: 39th Annual conference of the IEEE industrial electronics society. IECON, pp. 1741-1748, 2013.

[4] El Khateb A, Rahim NA, Slvarj J, Uddin MN., "Fuzzy logic controller based SEPIC converter for maximum power point tracking," IEEE Trans Ind Appl, vol. 50, pp. 2349-2358, 2014.

[5] Garraoui, Radhia, Hamed, Mouna Ben, and Sbita, Lassaad, "MPPT Controllers Based on Sliding-Mode Control Theory and Fuzzy Logic in Photovoltaic Power Systems: A Comparative Study," In : Applications of Sliding Mode Control. Springer, pp. 215-231, 2017.

[6] Abdelsalam, Ahmed K., Massoud, Ahmed M., Ahmed, Shehab, et al., "High-performance adaptive perturb and observe MPPT technique for photovoltaic-based microgrids," IEEE Transactions on Power Electronics, vol. 26, no. 4, pp. 1010-1021, 2011.

[7] Bianconi, E., Calvente, J., Giral, R., Mamarelis, E., Petrone, G., Ramos-Paja, C.A., Spagnuolo, G., Vitelli, M., "Perturb and Observe MPPT algorithm with a current controller based on the sliding mode," Int. J. Electr. Power Energy Syst, vol. 44, pp. 346-356, 2013.

[8] Bianconi, E., Calvente, J., Giral, R., Mamarelis, E., Petrone, G., Ramos-paja, C.A., Spagnuolo, G., Vitelli, M., “A Fast Current-Based MPPT Technique Employing Sliding Mode Control,” IEEE Trans. Ind. Electron, vol. 60, pp. 1168-1178, 2013.

[9] T. Esram, and P. L. Chapman, "Comparison of Photovoltaic Array Maximum Power Point Tracking Techniques," IEEE transactions on energy conversion, vol. 22, 2007.

[10] Y. Levron and D. Shmilovitz, "Maximum power point tracking employing sliding -mode control," IEEE Trans. on Circuits and Systems, vol. 60, pp.724-731, 2013.

[11] Chu, Chen-Chi and Chen, Chieh-Li, "Robust maximum power point tracking method for photovoltaic cells: A sliding mode control approach," Solar Energy, vol. 83, no. 8, pp. 1370-1378, 2009.

[12] Levron, Yoash and Shmilovitz, Doron, "Maximum power point tracking employing sliding mode control," IEEE Transactions on Circuits and Systems I: Regular Papers, vol. 60, no 3, pp. 724-732, 2013.

[13] Pan, Tinglong, Ji, Zhicheng, and Jiang, Zhenhua, "Maximum power point tracking of wind energy conversion systems based on sliding mode extremum seeking control," In : 2008 IEEE Energy 2030 Conference. IEEE, pp. 1-5, 2008.

[14] Rekioua, D., Achour, A. Y., and Rekioua, T., "Tracking power photovoltaic system with sliding mode control strategy," Energy Procedia, vol. 36, pp. 219-230, 2013.

[15] Salmi, Tarak, Bouzguenda, Mounir, Gastli, Adel, et al., "Matlab/simulink based modeling of photovoltaic cell," International Journal of Renewable Energy Research (IJRER), vol. 2, no. 2, pp. 213-218, 2012.

[16] Villalva, Marcelo Gradella, Gazoli, Jonas Rafael, and Ruppert Filho, Ernesto, "Modeling and circuit-based simulation of photovoltaic arrays," In : 2009 Brazilian Power Electronics Conference. IEEE, pp. 1244-1254, 2009.

[17] N. Tariba, A. Haddou, Haf. El Omari and Ham. El Omari, "Design and implementation an Adaptive Control for MPPT systems using Model Reference Adaptive Controller," 2016 International Renewable and Sustainable Energy Conference (IRSEC), pp. 165-172, 2016.

[18] SCHOTT: Schott Perform ${ }^{\mathrm{TM}}$ Poly series, [Online]. Available: http://ozzyfortunegroup.com.au/wp-content/ uploads/2015/01/SH-DATA-QA-001-SCHOTT-PERFORM-POLY-235-250-EN-0812-V0.pdf

[19] T. Esram and P. L. Chapman, "Comparison of photovoltaic array maximum power point tracking techniques," IEEE Trans. Energy Convers, vol. 22, no. 2, pp. 439-449, 2007.

[20] H. S. Bae, S. J. Lee, K. S. Choi, B. H. Cho, and S. S. Jang, "Current control design for a grid connected photovoltaic/fuel cell DC-AC inverter," in Proc. 24th IEEE APEC, pp. 1945-1950, 2009.

[21] Liu, C., Wu, B., and Cheung, R., "Advanced algorithm for MPPT control of photovoltaic systems," In : Canadian Solar Buildings Conference, 2004.

[22] Kasa, Nobuyuki, Iida, Takahiko, and Majumdar, Gourab, "Robust control for maximum power point tracking in photovoltaic power system," In : Proceedings of the Power Conversion Conference-Osaka 2002 (Cat. No. 02TH8579). IEEE, pp. 827-832, 2002.

[23] Rahim, Nasrudin A., Chaniago, Krismadinata, and Selvaraj, Jeyraj, "Single-phase seven-level grid-connected inverter for photovoltaic system," IEEE transactions on industrial electronics, vol. 58, no. 6, pp. 2435-2443, 2011.

[24] LO, Yu-Kang, Lee, Ting-Peng, and Wu, Kuan-Hung, "Grid-connected photovoltaic system with power factor correction," IEEE Transactions on Industrial Electronics, vol. 55, no. 5, pp. 2224-2227, 2008.

[25] Walker, Geoffrey R. and Sernia, Paul C., "Cascaded DC-DC converter connection of photovoltaic modules," IEEE transactions on power electronics, vol. 19, no. 4, pp. 1130-1139, 2004. 
[26] Bryant, Brad and Kazimierczuk, Marian K., "Open-loop power-stage transfer functions relevant to current-mode control of boost PWM converter operating in CCM," IEEE Transactions on Circuits and Systems I: Regular Papers, vol. 52, no. 10, pp. 2158-2164, 2005.

[27] Rogers, Everett, "Understanding boost power stages in switchmode power supplies," TI Literature No. SLVA061, 1999.

[28] Farahat, M. A., Metwally, H. M. B., and Mohamed, Ahmed Abd-Elfatah, "Optimal choice and design of different topologies of DC-DC converter used in PV systems, at different climatic conditions in Egypt," Renewable Energy, vol. 43, pp. 393-402, 2012.

[29] L. Fridman, Y. Shtessel, C. Edwards and Xing-Gang Yan, "High-order sliding-mode observer for state estimation and input reconstruction in nonlinear systems," International Journal of robust and nonlinear control, vol. 18, no.4-5, pp. 399-413, 2008.

[30] I. Boiko, L. Fridman, A. Pisano, and Usai, "Analysis of chattering in system with second order sliding modes," IEEE Transactions on Automatic Control, vol. 52, no. 11, pp. 2085-2102, 2007.

[31] Yau, Her-Terng, "Design of adaptive sliding mode controller for chaos synchronization with uncertainties," Chaos, Solitons \& Fractals, vol. 22, no. 2, pp. 341-347, 2004.

[32] Tan, Siew-Chong, Lai, Yuk-Ming, and Tse, Chi K., "A unified approach to the design of PWM-based sliding-mode voltage controllers for basic DC-DC converters in continuous conduction mode," IEEE Transactions on Circuits and Systems I: Regular Papers, vol. 53, no. 8, pp. 1816-1827, 2006.

[33] Xu, Jian-Xin, Pan, Ya-Jun, and Lee, Tong-Heng, "Analysis and design of integral sliding mode control based on Lyapunov's direct method," In: Proceedings of the 2003 American Control Conference, IEEE, pp. 192-196, 2003.

[34] Tan, Siew-Chong, Lai, Y. M., and Chi, K. Tse, "Indirect sliding mode control of power converters via double integral sliding surface," IEEE Transactions on Power Electronics, vol. 23, no. 2, pp. 600-611, 2008.

\section{BIOGRAPHIES OF AUTHORS}

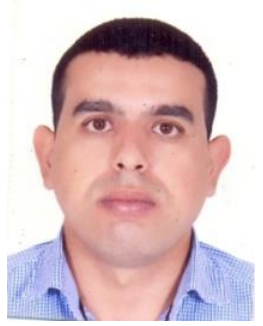

Nour-Eddine Tariba was born in Taza, Morocco, on November 1985. He received his Master Degree in Microelectronics from the IBN TOUFAIL University in Kénitra, Morocco. Currently, he works at Lear Corporation as a Hardware Electrification engineer. His current research interests include electronic design and control for high power electronics systems.

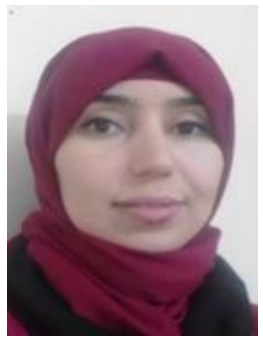

Naima Ikken was born in Oulmes in the Middle Atlas in Morocco. She graduated in renewable energy and system energy from HASSAN II University-Casablanca in 2013. Currently she is a Phd candidate in Physics and Engineering Science at the renewable Energy, Environment and Development Laboratory (ERED) of Hassan I University,Faculty of Science and Technology (FST), Settat-Morocco.

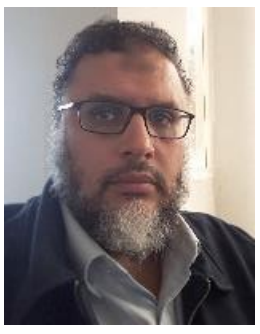

Ahmed Haddou was born in Khouribga, Morocco.onJune01, 1974. He graduated in electronic from Institute of Electronics, Microelectronics and Nanotechnology of The University of Valenciennes and Hainaut Cambrésis in France. For 20 years, Ahmed Haddouhave contributed to the development of hardware embedded systems programs in the automotive and aerospace industry in France and Morocco (VALEO, Hispano suiza, EADS, ADETEL MAROC, NSS MAROC).

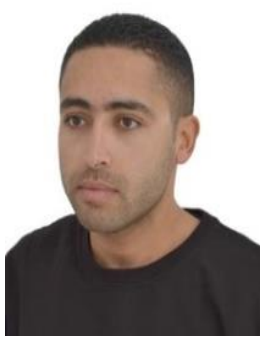

Abdelhadi Bouknadel was born in El jadida, Morocco, on February 26, 1989. He graduated in electromechanical from ENSAM "école nationale supérieur d'arts et métiers Meknès" in Morocco. After graduation, he worked as a full time employee with the Adeneo Group at ADETEL MAROC affiliate. His work at Adeneo has included electronic design, power electonic design and simulation, and system design. 

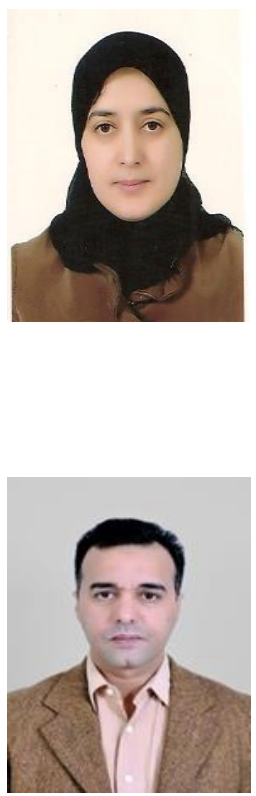

Hafsa El Omari was born on April 15, 1974 in Oulmès in the Middle Atlas in Morocco. She prepared her Advanced Studies Diploma (DEA) in microelectronics and a $\mathrm{PhD}$ Doctorate Degree in electrical engineering from INSA Lyon in France. Her doctoral thesis, carried out at the CEGELY laboratory, electrical engineering center at INSA Lyon, focused on the modeling and simulation of power components such as VDMOS, IGBT transistors, etc. She then spent two years as Temporary Teaching and Research Assistant (ATER) in the LAM automatic and electronics laboratory at the Champagne Ardenne University in Reims in France. In parallel to this training, she followed a Masters in IT management at INSA Lyon, and prepared other certificates in IT development at the Qualea center in Bron in France. Since 2007, she has been recruited to a teaching and research position at Hassan I University in Settat (ENCG-Settat). She is a permanent member of the laboratory for renewable energies, environment and development (LERED) at the FST in Settat.

Hamid El Omari was born on 12/09/1966 in Oulmès in the Middle Atlas in Morocco. Since November 1994, he obtained his PhD at the National Institute of Applied Sciences (INSA) of Lyon - Laboratory of Physics of Matter (in France). In 1998, He prepared the accreditation to supervise research (HDR) at INSA of Lyon in France. Its previous research activities have improved the quality ratio of multicrystalline silicon solar cells through the use of a new Anti-Reflective Coating deposition procedure (ARC before Screen Printing Contact deposition) that favours the reduction of the silicon reflection coefficient as well as the formation of good quality ohmic contacts. His work has also led to the implementation of a new method TLM (Transmission Line Model) for measuring contacts on multi-crystalline substrates (multicrystalline, polycrystalline, amorphous or porous). In 2006, Professor Hamid EL OMARI created the first Renewable Energy Laboratory in Morocco at Hassan Premier University. The various research activities under the supervision of Professor Hamid EL OMARI concern either green energy conversion systems (inverter; speed variator; simulations, study and metrology of photovoltaic stations; solar cars ...) or the storage in some forms of green energy (solar water heater; biodigester or biogas with cogeneration ...). All projects supervised by Professor Hamid EL OMARI are funded by the Research Institute of Solar Energy and New Energies (IRESEN) under the Ministry of Energy, Mining \& Sustainable Development in Morocco (whose inverter is the subject of this article), and the National Center for Scientific and Technical Research (CNRST) under the Ministry of Higher Education, Scientific Research and Executive Training of Morocco. 